\title{
CONTEXTO HISTÓRICO E POLÍTICO DA EDUCAÇÃO DAS PESSOAS COM DEFICIENCIA E OS DESAFIOS PARA A EDUCAÇÃO INCLUSIVA
}

\author{
HISTORICAL AND POLITICAL CONTEXT OF THE EDUCATION OF PEOPLE WITH \\ DISABILITIES AND THE CHALLENGES FOR INCLUSIVE EDUCATION \\ CONTEXTO HISTÓRICO Y POLÍTICO DE LA EDUCACIÓN DE LAS PERSONAS CON \\ DISCAPACIDAD Y LOS DESAFÍOS DE LA EDUCACIÓN INCLUSIVA
}

Fabricio de Lima Bezerra Silva*

(iD) https://orcid.org/oooo-00o2-6722-6704

David Espinola Batista**

iD https://orcid.org/oooo-0oo2-7637-8216

Munique Massaro***
iD https://orcid.org/oooo-0002-0294-0501

REVISTA PEDAGÓGICA

Revista do Programa de Pós-graduação em Educação da Unochapecó | ISSN 1984-1566 Universidade Comunitária da Região de Chapecó | Chapecó-SC, Brasil Como referenciar este artigo: SILVA, F. B. L.; BATISTA, D. E.; MASSARO, M. Contexto histórico e político da educação das pessoas com deficiência e os desafios para a educação inclusiva. Revista Pedagógica, Chapecó, v. 22, p. 1-23, 2020.

DOI: https://doi.org/10.22196/rp.v22io.5659

\begin{abstract}
RESUMO: A história das pessoas com deficiência é marcada pela sua exclusão na sociedade desde a préhistória. No Brasil, até por volta de 1970, elas eram segregadas por meio de uma prática assistencialista. Após muitas lutas e exigências de agências internacionais, há a implementação de políticas que articulam a Educação Especial com o sistema regular de ensino, primeiro para integração e, a partir da década de 1990, para a inclusão escolar. Assim, esse ensaio teórico, parte de uma dissertação de mestrado, tem como objetivo realizar o resgate histórico das concepções, práticas de cuidado e retratar a perspectiva de escolarização das pessoas com deficiência na realidade legislativa e no cenário escolar que busca ser inclusivo. As análises acerca dos desafios enfrentados pelos profissionais apontaram a necessidade de assegurar uma formação conivente com a realidade escolar, garantindo meios para que todos os alunos tenham acesso aos conhecimentos e principalmente êxito no processo de aprendizagem.
\end{abstract}

Palavras-chave: Educação Especial. Educação Inclusiva. Assistência ao Educando. Política da Educação. Formação dos Profissionais da Educação.
ABSTRACT: The history of people with disabilities is marked by their exclusion from society since prehistory. In Brazil, until around 1970, they were segregated through an assistentialist practice. After many struggles and demands from international agencies, policies are implemented that link Special Education with the regular education system, first for integration and, from the 1990 onwards, for school inclusion. Thus, this theoretical essay, part of a master's dissertation, aims to carry out the historical rescue of conceptions,

care practices and portray the perspective of schooling people with disabilities in the legislative reality and in the school scenario that seeks to be inclusive. The analyzes about the challenges faced by the professionals pointed out the need to ensure a training that connects with the school reality, guaranteeing the means for all students to have access to knowledge and especially success in the learning process.

Keywords: Special Education. Inclusive Education. Student Assistance. Education Policy. Training of Education Professionals.

RESUMEN: La historia de las personas con discapacidad está marcada por su exclusión de la sociedad desde la prehistoria. En Brasil, hasta alrededor de 1970, fueron segregados a través de una práctica asistencialista. Luego de muchas luchas y demandas de organismos internacionales, se implementan políticas que vinculan la Educación Especial con el sistema educativo regular, primero para la integración y, a partir de la década de 1990, para la inclusión escolar. Así, este ensayo teórico, que forma parte de una tesis de maestría, pretende realizar el rescate histórico de concepciones, prácticas de cuidado y retratar la perspectiva de escolarizar a las personas con discapacidad en la realidad legislativa y en el escenario escolar que busca ser inclusivo. El análisis de los retos a los que se enfrentan los profesionales señaló la necesidad de asegurar una formación que conecte con la realidad escolar, garantizando los medios para que todos los estudiantes tengan acceso a los conocimientos y sobre todo el éxito en el proceso de aprendizaje.

Palabras clave: Educación Especial. Educación Inclusiva. Asistencia a la Educación. Política Educativa. Formación de Profesionales de la Educación. 


\section{Introdução}

O presente artigo descreve parte de uma dissertação de mestrado em andamento que tem como propósito analisar a percepção de professores de Matemática acerca da prática pedagógica no processo de inclusão escolar de alunos com deficiência. Aqui, propõe-se uma discussão de cunho teórico, recorte do estudo realizado na dissertação, sobre os aspectos históricos relevantes de como as pessoas com deficiência eram concebidas pela sociedade e, a partir desta, situar as mudanças ocorridas no sistema público de ensino brasileiro, incentivada pela luta das pessoas com deficiência e criação de legislações que garantem o acesso, a permanência e a aprendizagem de alunos com deficiência, transtornos globais de desenvolvimento e altas habilidades/superdotação nas escolas em salas regulares de ensino.

Cabe iniciar essa discussão apontando que nos últimos anos, e com mais afinco a partir de 1990, o contexto educacional tem se configurado mais desafiador diante a inserção de alunos com deficiência nas escolas regulares de todo o país, em decorrência da criação de políticas nacionais inclusivas. Desta forma, se tem requerido do sistema de ensino, como imprescindível, condições educativas que proporcionem o desenvolvimento intelectual e sociocultural dos diferentes indivíduos por meio da oferta de serviços voltados para as necessidades educacionais de todos os alunos. Sendo assim, registra-se uma maior preocupação em discutir e compreender a escolarização de alunos com deficiência nesses espaços.

A instituição de ensino tem se tornado um ambiente onde, constantemente, se colocam os alunos sob uma percepção vertical de aprendizagem, assumindo sobreposições dos alunos com boa produtividade acima dos alunos com baixa produtividade. Nesse sentido, a escola, bem como a sociedade, cria situações idealizadas por categorias de valorização pelo rendimento, como também de acordo com a capacidade de execução de atividades. Um exemplo são as atividades esportivas, que se não forem adaptadas, o aluno com deficiência física estará em possíveis desvantagens, acarretando situações de exclusão.

O desafio criado sob o discurso das ações para fins de uma escola inclusiva está posto em uma sociedade, como se destacou, ainda excludente. A perspectiva de inclusão estabelece a necessidade de uma nova dimensão a ser compreendida pela coletividade que ainda vivencia esse cenário supressório. No processo educativo, cabe ao professor estabelecer relações com seus alunos de forma a mediar e buscar práticas efetivas que proporcionem uma educação escolar pautada na formação do aluno como um sujeito social, de maneira que o professor compreenda seu papel

\begin{abstract}
* Mestrando em Educação pela Universidade Federal da Paraíba. Especialista em Ensino de Língua Portuguesa e Matemática em uma Perspectiva Transdisciplinar pelo Instituto Federal do Rio Grande do Norte. Licenciado em Matemática pela Universidade Federal da Paraíba.E-mail: ho.15@hotmail.com
\end{abstract}

** Licenciado em Ciências Biológicas e mestrando em Educação pela Universidade Federal da Paraíba. E-mail: david_jpbr@yahoo.com.br

*** Doutora em Educação, linha Educação Especial, pela Universidade Estadual Paulista (UNESP), com doutorado sanduíche na Universidade de Oslo - Noruega (2016). Professora Adjunto do departamento de Habilitações Pedagógicas e do Programa de Pós-Graduação em Educação da Universidade Federal da Paraíba, campus João Pessoa. Líder do Grupo de Estudos e Pesquisa em Educação Especial (GEPE) certificado pelo CNPq.E-mail: munique@ce.ufpb.br 
como importante na produção dessas situações (SPEROTO; CARLESSO, 2013).

Aspira-se que a escola possa assinalar a necessidade de concepção da diferença em nossa realidade, através de sua prática pedagógica não isolada em seus muros. A abordagem temática se desenha não apenas como uma escolha resumida a estudos e reflexões, mas também pela necessidade democrática e ética de nosso sistema educacional, que deve formar práticas inclusivas. $\mathrm{O}$ paradigma da inclusão não deve se restringir aos discursos nas universidades, embora haja necessidade dessas interlocuções coletivas, mas deve-se efetivar, prontamente, exercendo transformações na sociedade.

Assim, esse estudo teórico tem por objetivo realizar o resgate histórico das concepções, práticas de cuidado e, finalmente, retratar a perspectiva de escolarização das pessoas com deficiência na realidade legislativa e no cenário escolar para o modelo educativo que busca ser inclusivo. $\mathrm{O}$ artigo se propõe a retratar como as pessoas com deficiência eram assistidas pelas entidades filantrópicas em decorrência da concepção histórica que potencializou sua exclusão, resgatando concepções e práticas de cuidados destinadas a esses indivíduos. Em seguida, são apontados alguns marcos legislativos no Brasil que focalizam os principais acontecimentos destinados à escolarização de alunos que são público-alvo da Educação Especial, como também são extraídos estudos que retratam, sobre essa perspectiva, a realidade no país diante dos desafios da inclusão. Por fim, são tecidas algumas considerações que, a partir do estudo, inferem para futuras discussões.

\section{Breve histórico acerca dos cuidados com a pessoa com deficiência}

Vistas como defeituosas, as pessoas com deficiência foram marcadas por um impiedoso traço histórico que as colocaram completamente restritas à margem da sociedade. De acordo com Correia (1999 apud COSTA, 2012), as crianças na Idade Antiga que nasciam com alguma má-formação eram sacrificadas e, por vezes, as famílias as abandonavam, sendo considerada uma prática legítima. De acordo com Martins (2011 apud KRANZ, 2015, p. 65), "na Antiguidade as pessoas com deficiência eram eliminadas, devido a sua incapacidade para participação em atividades necessárias à sobrevivência do coletivo.”

Para Walber e Silva (2006), as pesquisas antropológicas relatam a presença de pessoas com deficiência desde a Pré-História, evidenciadas a partir de sua retratação em pinturas e cerâmicas. A população agia ora aceitando as pessoas com deficiência e doentes como membros da 
comunidade, ora desclassificando-as de maneira a eliminá-las. Essa prática de eliminação também era conduta estabelecida pelos gregos e foi frequente até meados do ano 280 da Era Cristã, em Roma. Assim, "bebês considerados anormais eram abandonados em cestas enfeitadas com flores às margens do rio e eram recolhidos por familiares pobres que os criavam para depois se utilizarem deles para pedir esmolas." (WALBER; SILVA, 2006, p. 30).

Adiante, os cuidados com as pessoas com deficiência passaram a ser realizados pelas igrejas, que forneciam moradia e condenavam a ação de eliminação antes propagada. Isso se sucedeu com o Cristianismo (século IV), permitindo que fosse dado afeto a essas pessoas, a partir do entendimento de que elas também eram criações divinas, ou seja, "filhas de Deus" e necessitavam de atenção (KRANZ, 2015). Já no século XV, as pessoas com deficiência foram rotuladas como loucas pela população. As pessoas acreditavam que espíritos malignos habitavam nas pessoas com deficiência. Elas foram levadas à fogueira por parte da Inquisição ${ }^{1}$ e, entendendo que essa ação era necessária, se constituiu como costume até o século XVI.

Denominadas como práticas assistencialistas a partir do final da Idade Média, as pessoas com deficiência, como também algumas pessoas consideradas carentes, passaram a receber atenção por instituições que buscavam integrá-las na comunidade. Todavia, eram definidos critérios para que esses indivíduos recebessem assistências: "o primeiro seria o do 'pertencimento comunitário' que vincula a assistência à condição de ser membro do grupo, rejeitando assim os 'estrangeiros'. Um segundo critério era o da 'inaptidão para o trabalho'." (WALBER; SILVA, 2006, p. 31).

Foi presenciado, no período da Idade Moderna, um interesse por parte da medicina em relação à educação das pessoas com deficiência. Porém, ainda permaneceram atitudes de exclusão advindas da sociedade, prevalecendo uma notação sobre a patologia. As deficiências começaram a ser estudadas e os aspectos biológicos eram evidenciados (MIRANDA, 2008).

O que se constatou, em sequência, foi o tratamento das pessoas com deficiência como sujeitos propícios a cometer crimes, concepção que também associava a deficiência à prostituição e à pobreza. Aos médicos, foi concedido o poder para decidir, dentre as pessoas com deficiência, quais seriam julgadas, condenadas e salvas, exercendo também uma categorização quanto à deficiência, um tipo de classificação feita pela medicina para prestação de atendimento em locais que antes entendiam-se como especializados e valiam como assistencialismo. Depois, esses espaços foram alterados para atuarem de forma individual a partir das categorizações realizadas aos sujeitos. A atenção
$1 \mathrm{Ou}$, Tribunal do Santo Ofício da Inquisição, "ao Santo Ofício, caberia a função de manter a diferença entre as classes que havia sido diluída com a conversão forçada, defendendo os interesses da camada dominante." "A presença da Inquisição no Brasil relaciona-se à atitude de expansão dos órgãos de controle do próprio Estado." (ASSIS, 2002, p. 49-52). 
aos cuidados à pessoa com deficiência se deu em um despertar "a partir da Revolução Industrial, quando as guerras, as epidemias e anomalias genéticas deixaram de ser causas únicas das deficiências, e o trabalho, em condições precárias, passou a ocasionar os acidentes mutiladores e doenças profissionais." (SOUZA, R., 2009, p. 36).

Na década de 1960, os registros são de práticas que tinham como conceito que as pessoas com deficiência "poderiam e deveriam participar da sociedade, desde que se adaptassem às normas e valores sociais" (WALBER; SILVA, 2006, p. 34), o que não ocorreria. Nessa direção, pensava-se em uma "normalização" das pessoas com deficiência que jamais poderia ser efetivada. Ainda na década referida, de acordo com as autoras, existiram indagações quanto ao assistencialismo oferecido, contestando os serviços concedidos a essa população que deveriam permitir que as pessoas com deficiências atuassem como membro social.

A contar dos movimentos, as instituições que prestavam serviços às pessoas com deficiência acabaram tendo que se ajustar e, com isso, o sistema educacional também passou a analisar o atendimento prestado a esses indivíduos. Estes começaram a frequentar salas de aula que, em sua maioria, eram compostas por pessoas sem deficiência e, assim, as escolas passaram a questionar as técnicas pedagógicas desenvolvidas e os métodos necessários para atender à diversidade.

No final do século XIX e meados do século $\mathrm{XX}$, surge o desenvolvimento de escolas e/ou classes especiais em escolas públicas, visando oferecer à pessoa deficiente ${ }^{2}$ uma educação à parte. Por volta da década de 1970, observa-se um movimento de integração social dos indivíduos que apresentavam deficiência, cujo objetivo era integrá-los em ambientes escolares, o mais próximo possível daqueles oferecidos à pessoa normal ${ }^{3}$. (MIRANDA, 2008, p. 30).

Até então não era oferecida educação às pessoas com deficiência. Na verdade, o que se tinha era uma oferta elitista, onde, em pequenos casos, as famílias que possuíam riquezas ofereciam atendimentos educacionais aos membros de sua classe familiar ou, ainda, buscavam preparar a pessoa com deficiência, em ambiente isolado, para torná-la apta a exercer alguma atividade (SOUZA, R., 2009). Nesse seguimento, em o9 de dezembro de 1975, a Declaração dos Direitos das Pessoas Deficientes, resolução aprovada pela Assembleia Geral da Organização das Nações Unidas (ONU), proclamou que
2 Atualmente, a utilização deste termo não é adequada, pois a pessoa com deficiência não é deficiente, ela possui uma deficiência, porém, se preservou a citação para manter a perspectiva histórica da época.

3 A patologia, categorizada pela medicina na época, estaria relacionada à pessoa com deficiência, portanto, a pessoa normal é conceituada pela ausência patológica. 
o termo "pessoas deficientes" refere-se a qualquer pessoa incapaz de assegurar por si mesma, total ou parcialmente, as necessidades de uma vida individual ou social normal, em decorrência de uma deficiência, congênita ou não, em suas capacidades físicas ou mentais. (ONU, 1975, p. 1).

Em 1981, considerado pela ONU o Ano Internacional das Pessoas Deficientes, foi chamada a atenção da sociedade para que compreendesse seu encargo na busca por processos inclusivos, de maneira que contemplasse a pessoa com deficiência como parte dela. $\mathrm{E}$ assim, o corpo social, emparelhado com as pessoas com deficiência, buscou a construção de práticas inclusivas. Por não haver um caminho único, as atividades sociais começaram a ser reestruturadas e novos trajetos foram sendo constituídos para solucionar os desafios.

Com a Convenção Internacional sobre os Direitos das Pessoas com Deficiência das Nações Unidas e seu Protocolo Facultativo, assinados em Nova York, em 30 de março de 2007, que se estabeleceu como referência às políticas públicas direcionadas às pessoas com deficiência, foi delimitado no primeiro artigo uma outra concepção de deficiência, vigente atualmente:

Pessoas com deficiência são aquelas que têm impedimentos de longo prazo de natureza física, mental, intelectual ou sensorial, os quais, em interação com diversas barreiras, podem obstruir sua participação plena e efetiva na sociedade em igualdade de condições com as demais pessoas. (BRASIL, 2009).

Atualmente, não é possível falar que se tenha superado as condutas assistencialistas que foram se constituindo na trajetória descrita, que envolveram a atenção e serviços prestados pela igreja e os modelos de categorização por parte da medicina, resultando em um desapreço às pessoas com deficiência. Essas perspectivas ainda estão presentes na sociedade atual, pois são traduzidas como soluções e são reinventadas (WALBER; SILVA, 2006). Para tanto, a seção a seguir constitui-se numa discussão sobre as ações que, em contexto nacional, estabelecem caminhos em defesa das pessoas com deficiência, buscando uma educação para todos e realçando a tentativa de formar processos inclusivos.

\section{Alguns marcos históricos e legais da educação especial no Brasil}

No Brasil, como em outros países, as tentativas de integração das pessoas com deficiência na sociedade se mos- 
traram tão somente possível a partir do esforço unicamente atribuído a elas de reproduzir condutas de normalização já impostas pela população, como, por exemplo, de se admitirem autônomas e capazes de superar dificuldades apresentadas nos diversos espaços. Para tanto, as barreiras encontradas pelas pessoas com deficiência as impedia de assumir a normalização social imposta. Com isso, algumas instituições foram responsáveis pela internação desses sujeitos com o propósito de aproximá-los cada vez mais ao padrão compreendido como normal (WALBER; SILVA, 2006).

Frente a esse cenário, são criadas instituições que se destinavam a abrigar pessoas com algum tipo de deficiência (física, sensorial e/ou múltipla). Essas intenções foram remotas, segundo Bueno (1993). As pessoas com deficiência eram consideradas sem valor, portanto, colocá-las em instituições era uma forma de mantê-las isoladas da grande população. Desse modo, o marco da Educação Especial no Brasil se dá com a fundação na cidade do Rio de Janeiro, em 1854, do Imperial Instituto dos Meninos Cegos, hoje por nome de Benjamin Constant, e o Instituto dos Surdos-Mudos, em 1857, hoje Instituto Nacional de Educação de Surdos, instituições com dedicação à Educação Especial (COSTA, 2012).

Em 1900, segundo Bueno (1993), a saúde pública em São Paulo adotou medidas de inspeção nas instituições escolares buscando atuar, atraídos pelas pessoas com deficiência, com a prestação de serviços de higiene "mental e saúde pública, que em alguns estados deu origem ao serviço de Inspeção médico-escolar e à preocupação com a identificação e educação dos estados anormais de inteligência." (MENDES, 2010, p. 95). E então, a partir dessa atuação, a concepção da pessoa com deficiência se constituiu como prática de divisão feita por especialista com propósitos de dissociar a população dos denominados “diferentes".

A ajuda prestada pelas entidades, que em grande maioria eram de cunho religioso e outras privadas, demonstraram uma atuação assistencialista importante em todo território nacional, com atendimentos em áreas específicas. Porém, o que se comprova é o exercício de direito à cidadania não aplicado às pessoas com deficiência pela forma como se perpetuava uma compaixão da comunidade em prestar serviços a esses indivíduos.

De acordo com Januzzi (1992 apud MENDES, 2010), no período de 1930 a 1949, se constatou a criação de instituições privadas especializadas no ensino para pessoas com deficiência que se sobressaíram quando comparadas a quantidade de escolas da rede pública, número quatro vezes menor.

Sob considerações feitas por Bueno (1993) e complementadas posteriormente por Mendes (2010), entende-se 
com clareza o percurso realizado após a Segunda Guerra Mundial (1939-1945), que compreendeu a implementação dos Serviços de Educação Especial nas Secretarias Estaduais de Educação pelo país, onde foi possível perceber ações do Ministério da Educação e Cultura destinadas à educação das pessoas com deficiência. Houve a destinação de recursos financeiros às secretarias e entidades privadas especializadas, bem como campanhas que, em rede nacional, acentuavam a importância para a educação das pessoas com deficiência.

Evidenciou-se, nessa época, um movimento de privatização da educação especial, e em seguida, na década de 1960, a orientação para a privatização do ensino regular. Ainda nesse caminho, acreditava-se que as escolas regulares deveriam seguir recomendações médicas, as quais agiam na recusa de matrículas de alunos com deficiência, por entenderem que eles seriam a causa para o fracasso escolar.

Com essas atividades em nível nacional, surgem centros de reabilitação e instituições com atendimentos voltados às crianças com deficiências para áreas da deficiência física, visual e auditiva, juntamente com novas escolas privadas que, nas décadas de 1960 e 1970, assumiram um amplo atendimento e acabaram por ocupar espaço nas decisões políticas, que se destinaram à organização da Educação Especial. Com isso, foi criado uma divisão no atendimento aos alunos dessa modalidade de ensino que, "enquanto os excepcionais ${ }^{4}$ das camadas populares continuaram sendo objetos da assistência e caridade públicas, passou-se a se oferecer aos excepcionais das elites serviços que garantiam seus direitos em relação à saúde e educação.” (BUENO, 1993, p. 96).

O primeiro documento de Diretrizes e Bases da Educação Nacional, Lei ${ }^{0}$ 4.024 de 20 de dezembro de 1961, foi, segundo Mendes (2010), um marco na área da Educação Especial e fixou, no título X que:

Art. 88. A educação de excepcionais, deve, no que for possível, enquadrar-se no sistema geral de educação, a fim de integrá-los na comunidade.

Art. 89. Toda iniciativa privada considerada eficiente pelos conselhos estaduais de educação, e relativa à educação de excepcionais, receberá dos poderes públicos tratamento especial mediante bolsas de estudo, empréstimos e subvenções. (BRASIL, 1961).

Com o crescimento já evidenciado da Educação Especial, a década de 1970 é, então, uma representativa época na implementação de escolas e classes especiais, como também da formação, em todas as Secretarias Estaduais
4 Termo usado no período para designar as pessoas com deficiência. 
de Educação, dos Serviços de Educação Especial. Ainda em 1973, o Decreto $\mathrm{n}^{0} 72.425$ de 3 de julho, instituiu o Centro Nacional de Educação Especial (CENESP), primeira entidade responsável, no governo federal, por atuar nas políticas educacionais voltadas à Educação Especial. No art. $1^{\mathrm{o}}$ determinou, por finalidade do órgão: a promoção, em território nacional, do atendimento aos excepcionais; e, em parágrafo único concedeu ao CENESP autonomia para exercer atividades de supervisão nas secretarias municipais. Ademais, o art. $2^{\circ}$ decidiu que o CENESP:

Atuará de forma a proporcionar oportunidades de educação, propondo e implementando estratégias decorrentes dos princípios doutrinários e políticos, que orientam a Educação Especial no período pré-escolar, nos ensinos de $1^{\mathrm{O}}$ e $2^{\mathrm{O}}$ graus, superior e supletivo, para os deficientes da visão, audição, mentais, físicos, educandos com problemas de conduta para os que possuam deficiências múltiplas e os superdotados, visando sua participação progressiva na comunidade. (BRASIL, 1973).

Já na década de 1990, marcou no Brasil um período em que o sistema público educacional enfrentou problemas diante do grande número de alunos reprovados, constituindo, assim, indivíduos com baixos níveis de rendimento. Com isso, se propaga, de forma equivocada, a transferência desses alunos com baixo rendimento para as classes especiais. Ademais, de acordo com Mendes (2010), o Brasil tinha uma população que se encontrava com alto índice de pobreza. Diante disso, um grande número de alunos atendidos nos sistemas de ensino especial pertencia a essa classe e, atrelado a esse público, se instalou um conceito de pessoa com deficiência.

$\mathrm{O}$ direito de toda criança à educação foi reconhecido na Conferência Mundial sobre Educação para Todos, realizada em Jomtien, Tailândia, de 5 a 9 de março de 1990, onde foi proclamada a Declaração Mundial sobre Educação para Todos: satisfação das necessidades básicas de aprendizagem (o Brasil é signatário da Declaração). Inicialmente, a Declaração relata o enfrentamento aos altos índices de crianças que não têm acesso à educação, citando exemplos de problemas no âmbito econômico e ambiental que "[...] atropelam os esforços envidados no sentido de satisfazer as necessidades básicas de aprendizagem, enquanto a falta de educação básica para significativas parcelas da população impede que a sociedade enfrente esses problemas com vigor e determinação.” (UNESCO, 1990, p. 2).

A oportunidade dada às famílias de matricularem seus filhos com deficiência em escolas regulares, segundo explica Kranz (2015) por meio de reflexões de Martins 
(2006), Fernandes e Healy (2010), só foi possível no Brasil no fim dos anos 90, sob destaque da Conferência Mundial de Educação Especial como propulsora, que proclamou a Declaração de Salamanca, a qual o Brasil também é signatário. Realizada em Salamanca, na Espanha, e com cooperação da Organização das Nações Unidas para a Educação, a Ciência e a Cultura (Unesco), a conferência, que foi realizada entre 7 e 10 de junho de 1994, foi afirmativa a assegurar como dever dos Estados oferecer e garantir educação às pessoas com deficiência e propiciar sua participação no sistema em classes regulares, buscando dar oportunidades para que elas desenvolvam, como toda e qualquer criança, seu maior nível de aprendizagem.

A Declaração de Salamanca, nesse seguimento, considerou que a escola deve ser estruturada de modo que ela alcance "[...] crianças deficientes e superdotadas, crianças de rua e que trabalham, crianças de origem remota ou de população nômade, crianças pertencentes a minorias linguísticas, étnicas ou culturais, e crianças de outros grupos desavantajados ou marginalizados." (UNESCO, 1994, p. 3). Além disso, se atribuiu a cada governo o fundamental processo de aperfeiçoamento dos sistemas educacionais para que sejam exercidas atividades que valorizem todos os alunos, independentemente de sua individualidade, para endossar "a perspectiva de escolarização inclusiva e apoiar o desenvolvimento da educação especial como parte integrante de todos os programas educacionais." (UNESCO, 1994, p. 2, grifo nosso). Assim, o que se entende por Educação Inclusiva? E, atualmente, quem é o público-alvo da Educação Especial?

Educação Inclusiva “[...] é o processo de inclusão dos alunos com necessidades especiais, da pré-escola ao ensino superior. Escola inclusiva é aquela onde não existem campos demarcados, é preciso escapar dessa dicotomia, pois todos os educandos fazem parte da escola." (FILHO; BARBOSA, 2015, p. 353).

A Educação Inclusiva não impõe linhas que possam criar divisões entre os alunos sem deficiência e os alunos com deficiência, ou de uma forma mais geral, alunos com necessidades educacionais especiais, mas, as ações das "escolas inclusivas propõem um modo de organização do sistema educacional que considera as necessidades de todos os alunos e que é estruturado em função dessas necessidades." (MANTOAN, 2003, p. 16).

Na Lei $\mathrm{n}^{0} 12.796$, que altera a Lei de Diretrizes e Bases da Educação Nacional, lê-se: "entende-se por educação especial, para os efeitos desta Lei, a modalidade de educação escolar oferecida preferencialmente na rede regular de ensino, para educandos com deficiência, transtornos globais do desenvolvimento e altas habilidades ou 
superdotação." (BRASIL, 2013). O seguinte texto da lei é de 9 de abril de 2013. Essa modalidade de ensino mencionada, vale a ressalva, percorre todos os níveis de educação.

Posteriormente a Declaração de Salamanca (UNESCO, 1994), o Brasil, orientado pelo princípio da inclusão e com intenções de diminuir a desigualdade social, atestou políticas que buscaram avançar na inclusão dos grupos que historicamente foram alvos de discriminação. Entretanto, somente após 14 anos se instituiu uma política de educação regulamentando as mudanças na escola para a inclusão de pessoas com deficiência.

Para a Política Nacional de Educação Especial na perspectiva da Educação Inclusiva (BRASIL, 2008), o aluno público-alvo da educação especial (PAEE) foi por muito tempo compreendido como indivíduo que fazia parte de um sistema educacional separado do que prestava serviços aos alunos de educação comum. Somente a partir da Declaração de Salamanca é que se pensou em uma proposta escolar a fim de incorporar processos inclusivos, para que os alunos público-alvo da educação especial pudessem frequentar salas regulares. Essa perspectiva foi "a forma mais avançada de democratização das oportunidades educacionais, na medida em que a maior parte dessa população não apresentava nenhuma característica intrínseca que não permita tal inclusão.” (BUENO, 1999, p. 8). Desta forma, a escola passa a atender a todos os alunos numa tentativa de valorização individual e buscando a criação de ambientes que combatam a discriminação.

Nessa busca por um sistema educacional inclusivo, uma importante conquista na legislação brasileira, garantindo avanços no reconhecimento da pessoa com deficiência, foi a Lei ${ }^{0} 13.146$, de 6 de julho de 2015, que instituiu a Lei Brasileira de Inclusão da Pessoa com Deficiência (Estatuto da Pessoa com Deficiência), "destinada a assegurar e a promover, em condições de igualdade, o exercício dos direitos e das liberdades fundamentais por pessoa com deficiência, visando à sua inclusão social e cidadania.” (BRASIL, 2015). Afirma-se que as barreiras que são instauradas pela sociedade em espaços físicos e sociais impedem a participação efetiva de todos, inclusive da pessoa com deficiência.

Almeja-se, assim, alcançar uma qualidade no sistema de ensino já cobrada pelas próprias pessoas com deficiência e nas medidas adotadas pela esfera política, e pressionada por agências de fomento que buscam priorizar uma educação adequada a toda população e principalmente aos alunos público-alvo da educação especial. Os movimentos de exclusão continuam acontecendo mesmo com a ampliação dos atendimentos aos alunos com deficiência em classes comuns. As escolas ainda geram movimentos que, 
embora se admitam o acesso, esses alunos não dispõem de professores capacitados e faltam recursos eficazes, logo, o sistema ainda se apresenta frágil (MENDES, 2010).

Não se nega o importante avanço na legislação que foi expresso na sociedade até aqui para a inclusão das pessoas com deficiência, principalmente quando se constatou os tempos de discriminação e graves preconceitos. No entanto, ainda há desafios para a efetividade da lei, sob a qual é "fator crucial para o desenvolvimento da educação brasileira e da inclusão escolar da grande parcela da população brasileira que foi excluída, ao longo do tempo, do processo educativo na escola." (VINENTE; DUARTE, 2016, p. 186). Portanto, o desafio em nosso país para ascensão das políticas educacionais concernentes aos alunos público-alvo da educação especial é uma realidade e incita que acendam discussões específicas para que se manifestem mecanismos efetivos de inclusão escolar, dado que a inclusão enuncia a aclamação de igualdade de oportunidades para todos.

\section{A modalidade de ensino em questão: desafios e avanços para a educação inclusiva}

A discussão pretendida se mostra necessária tanto quanto urgente. A educação numa perspectiva de favorecimento de processos educacionais inclusivos tem sido alvo de questões políticas, debates escolares e reflexões no âmbito de instituições formadoras de professores. Acredita-se que a partir da educação é possível superar as expressões de desigualdades que se vivencia na sociedade, a fim de que a escola subjugue as diferenças e que se compreenda que todos somos iguais e temos os mesmos valores.

Ainda assim, o debate sobre a desigualdade levanta a questão: como permitir a todas as pessoas com deficiência o acesso aos espaços que a sociedade dispõe, se ainda não superamos o problema de incluir as pessoas sem deficiência? Esse acentuado questionamento é trazido nas linhas iniciais da discussão proposta por Caiado (2014), numa tentativa de compreender que no Brasil, embora se busque a inclusão das pessoas com deficiência, há uma sociedade marcada por exclusões de outras pessoas, tornando a realidade contraditória e desafiadora.

A escola, no imaginário de muitas pessoas, é um lugar que deve ser respeitoso com as diferenças dos indivíduos, mas não é o que Costa (2012, p. 20) observa: "durante séculos nossa escola tem se configurado como celetista, excludente e, por conseguinte, conservadora, principalmente por privilegiar os bons, perfeitos, normais, enfim, os bem-construídos." Para transformar essa realidade, a escola precisa propiciar ao aluno uma visão heterogênea 
do mundo em que ele vive, permitindo-o compreender a diversidade e a respeitá-la.

O professor, que em sua prática atribui a si todo o conhecimento, é consoante em "pensar que a aprendizagem é homogênea e que as práticas necessariamente devam ser direcionadas igualmente para todas as pessoas." (COSTA, 2012, p. 56). Desta forma, falar que o educador é o único pertencente da ação de educar e o aluno é compreendido como o sujeito a ser educado, distancia-se do exercício de ampliação e valorização dos diferentes contextos que produzem aprendizagens. Para tanto, "educar na diversidade é respeitar a aprendizagem mesmo esta sendo heterogênea, onde todos aprendem claro, do seu jeito, de cada maneira em determinados momentos." (COSTA, 2012, p. 56).

Considera-se que é possível ter expectativas de ultrapassar alguns modelos excludentes já postos na educação, porém, os professores têm tido acesso ao conhecimento e às produções científicas sobre práticas inclusivas? Estão ocorrendo formações continuadas adequadas e com qualidade, não a distância e aligeiradas, na busca por promover a inclusão? Há recursos e serviços que atendam às necessidades dos alunos público-alvo da educação especial nos sistemas educacionais de ensino? Existe uma cultura escolar inclusiva e colaborativa nas escolas? Há vontade política e dos gestores da educação para promover, de fato, uma escola inclusiva? Há consciência e participação coletiva, da sociedade, incluindo as pessoas público-alvo da educação especial e seus familiares na busca de uma sociedade inclusiva? Ou seja, há diversos desafios que ainda precisam ser considerados e diversas barreiras que precisam ser identificadas para que possíveis soluções sejam construídas.

Relativo aos questionamentos acerca da formação de professores, Borba, Almeida e Gracias (2018) indagaram sobre essa distância entre universidade e escola e defenderam que as pesquisas precisam propor modelos que inovem o processo de ensino e aprendizagem com o objetivo de promover melhorias na formação de todos os alunos.

A respeito das famílias, ainda é possível encontrar aquelas que optam por isolar seus filhos com deficiência e acabam por não permitir que eles desenvolvam independência, conseguinte, passam a não frequentar a escola e a não terem oportunidades de aprendizagens que possibilitarão sua autonomia. É preciso que a família, observando a realidade, possa ser empoderada e possa atingir um grau de compreensão em sua responsabilidade de colaboração com o desenvolvimento de seus filhos.

A exclusão dos alunos com deficiência ao acesso à educação se configura por problemas de questões sociais e políticas, visto que neles há relações de poder que permeiam as instituições escolares. Propor que salas de aula 
sejam frequentadas por todos não se caracteriza em uma tentativa de tornar todos os alunos iguais. Entende-se que a partir dos fundamentos da Educação Inclusiva, as singularidades presentes em cada indivíduo sejam valorizadas, ao contrário de coibidas. Por essa razão, a escola deve buscar diminuir a segregação nos processos educativos e fortalecer o trabalho participativo de todos, considerando ainda que o aluno, independente da crítica a qual o tenha sido excluído pela diferença, deva se sentir parte do sistema escolar (SANTOS, 2006).

A participação do aluno que se busca, ultrapassa a atitude simplificada que o permite ser inserido na escola. Não que essa inserção seja irrelevante, mas não se deve construir somente condições para que ele esteja presente no contexto escolar. $\mathrm{O}$ que se pretende desenvolver são condutas que permitam ao aluno desenvolver suas máximas potencialidades, de maneira que haja adaptações na escola que vão além de estruturas físicas, que se compreenda o processo inclusivo como parte no gerenciamento escolar e configure novos entendimentos ao corpo docente. Atualmente, observa-se que a escola possibilita o acesso a todos os alunos público-alvo da educação especial, entretanto, não há garantia que suas práticas se constituam como inclusivas.

Desenvolver práticas inclusivas na escola requer do professor uma formação conivente. "Infelizmente, a demanda da inclusão chega às escolas antes da preparação do professor, e a solução tem sido a capacitação dos profissionais em serviço, através dos programas de formação continuada." (SERRA, 2006, p. 34).

A formação acadêmica, sozinha, não dá conta de formar professores para a criatividade e para a inclusão em educação, mas, certamente, é fundamental para desenvolver nos profissionais e futuros profissionais as potencialidades que permitirão a criação de culturas, políticas e práticas de inclusão. (SILVA, 2006, p. 55).

O que se constata em linhas gerais são as especificidades da educação perdendo espaço no processo de formação inicial do professor para dar lugar a uma formação que se concentra em técnicas gerais básicas, sendo insuficientes para lidar com os desafios do ensino. Nesse caminho, pelos ditames de Rocha e Lima (2018), é possível compreender que a formação inicial, sozinha, não consegue capacitar o professor para as diversas possibilidades que a escola pode apresentar é uma dessas é a reflexão sobre a Educação Especial. Sendo assim, a continuidade desse processo de formação acaba localizando-se na busca por especializações, 
pós-graduações stricto sensu ou cursos específicos, pois o professor entende que não se pode limitar-se apenas a sua formação inicial.

Entretanto, Santos e Moura (2018) evidenciaram resistências acerca desta perspectiva. Os autores buscaram compreender como o professor concebe o processo de inclusão em sua formação a partir da perspectiva e desafio da educação inclusiva. Os autores evidenciaram a compreensão de uma professora de sala comum sobre sua atuação, tendo em vista a frequência de um aluno com deficiência em sua sala. A professora de sala regular, embora admitisse a importância do trabalho realizado pela professora do Atendimento Educacional Especializado (AEE), tinha a crença na suficiência de subsídios, em sua formação inicial, para se trabalhar metodologias que contemplasse os alunos com necessidades educacionais especiais em salas comuns e, apesar de reconhecer os desafios do trabalho com inclusão de alunos PAEE, os autores concluíram que a professora se exime de uma formação continuada ofertada.

Nesse contexto, além da formação do professor do ensino regular, é urgente a necessidade de se pensar também na formação específica do professor da Educação Especial, que trabalha com o AEE. Atualmente, há somente duas universidades no Brasil, uma no Sul e outra no Sudeste - Universidade Federal de Santa Maria e Universidade Federal de São Carlos - que possuem formação inicial de licenciatura em Educação Especial. Em outros estados do Brasil, os professores do AEE também recorrem a cursos de especialização latu sensu em Educação Inclusiva, Educação Especial ou em Atendimento Educacional Especializado, na maioria das vezes, nas universidades privadas ou em cursos à distância. A formação do professor da Educação Especial para atuar tanto no Atendimento Educacional Especializado, como em instituições especializadas de Educação Especial vem sendo uma lacuna para contribuir para o processo de inclusão nas escolas brasileiras.

A oferta do Atendimento Educacional Especializado dá suporte para a elaboração de atividades pedagógicas acessíveis, tendo em vista as individualidades dos alunos público-alvo da educação especial. Os atendimentos individuais ou coletivos devem ocorrer no turno oposto ao que o aluno frequenta as aulas em sala comum, no intuito de que o atendimento não dificulte seu envolvimento nas atividades da classe comum (SANTOS; TORRES; MENDES, 2016). O AEE deve ser realizado, prioritariamente, nas Salas de Recursos Multifuncionais (SRM), porém, em articulação com o ensino regular. O espaço da sala dispõe de equipamentos e materiais, como móveis adaptados, materiais pedagógicos, de informática e de tecnologia assistiva (BRASIL, 2007). 
Evidencia-se que há escolas que possuem a SRM para o Atendimento Educacional Especializado dos alunos PAEE, no contraturno em que o aluno estuda na sala comum, entretanto, Faria e colaboradores (2020) verificaram em uma escola da rede pública municipal, que a oferta do AEE é ainda desafiadora. O público-alvo da educação especial matriculado na escola estudada é compreendido por 22 alunos (13 com deficiência intelectual, 3 com deficiências múltiplas e 6 diagnosticados com transtornos globais do desenvolvimento), porém apenas 12 alunos fazem uso da SRM. Os outros dez alunos não frequentam o AEE porque a família não pode levar o estudante. Em alguns casos a família se recusa ou, ainda, há alunos que optam por frequentar outra instituição que oferece o atendimento. Os autores concluíram que, mesmo com o considerável número de alunos fora da SRM, o sistema aponta como opcional para os familiares a frequência nesses espaços.

Atualmente, o Ministério da Educação tem adotado um modelo único na prestação de serviços aos alunos PAEE. Com isso, se concebe como inerente que os professores tenham conhecimento sobre as práticas que serão desenvolvidas no AEE, bem como as possibilidades e conceitos desse serviço. Assim, um outro desafio da inclusão é a qualidade desse serviço. É imprescindível avaliar como está ocorrendo o Atendimento Educacional Especializado nas escolas brasileiras, se está produzindo benefícios e se tem sido suficiente para suprir as necessidades educacionais especiais dos alunos PAEE (SANTOS; TORRES; MENDES, 2016). Fernandes e Massaro (2020) identificaram em duas escolas do Estado da Paraíba que três, das quatro professoras do ensino regular e do Atendimento Educacional Especializado, não tinham clareza das suas funções no atendimento aos alunos PAEE.

Contudo, o sistema brasileiro, considerando esse formato único de atendimento aos alunos PAAE, tem reduzido as possibilidades de desenvolvimento desses estudantes, por conta da diversidade dos alunos e das diferentes necessidades educacionais especiais. Em uma única sala de recurso, o professor especializado deve atender os diferentes tipos de alunos em suas diferentes escolaridades (MENDES; MALHEIRO, 2012).

As pesquisas apresentam que, muitas vezes, o professor acaba, de maneira equivocada, limitando à Educação Especial ao espaço proposto pelas SRM, provocando concepções negativas do trabalho isolado do Atendimento Educacional Especializado e resultando interferências ao processo de ensino e aprendizagem dos alunos e na construção de uma Educação Inclusiva. É necessário que o professor esteja preparado para lidar com a diferença, sendo capaz de se ajustar diante de desafios que porventura 
possam surgir, como desenvolver práticas colaborativas que permitam o aperfeiçoamento didático dos professores da sala comum e da SRM. O desenvolvimento da cultura do trabalho colaborativo nas escolas vem demonstrando ser fundamental para efetivar o processo de inclusão de alunos PAEE no ensino regular (FERREIRA et al., 2007, MATOS; MENDES, 2014, MENDES; VILARONGA; ZERBATO, 2014).

Com o objetivo de compreender como a escola considera o processo de inclusão de alunos PAEE em salas de aula comum, Vieira, Ramos e Simões (2019) evidenciaram que os professores e a coordenação pedagógica admitiam que as atividades pedagógicas não atendiam às necessidades dos alunos público-alvo da educação especial. A equipe escolar entendia que o próprio sistema de ensino colaborava com essa situação, pois se encarregava de não os reprovar no ano escolar. Na pesquisa, observou-se que os professores compreendiam que a SRM é importante para dar o apoio necessário ao aluno PAEE em sua aprendizagem. Mas os professores assumiram que "o olhar diante do aluno com deficiência era sempre construído com base nas impossibilidades e nas limitações, requisitando mudanças no processo e nas narrativas docentes." (VIEIRA; RAMOS; SIMÕES, 2019, p. 10).

Enfim, evidencia-se na pesquisa descrita que, embora houvesse condições possíveis de melhoria das práticas pedagógicas, o professor acaba por permanecer desenvolvendo estratégias limitadas que podem comprometer o processo de aprendizagem dos alunos, principalmente dos alunos com deficiência (VIEIRA; RAMOS; SIMÕES, 2019). Na busca por espaços que valorizem o aluno em sua particularidade, o professor é implicado a aperfeiçoar sua prática, articulando estratégias para favorecer a escolarização de todos no ensino regular, corroborando com uma prática inclusiva.

\section{Considerações finais}

Diante do exposto, é possível perceber avanços sobre a inclusão de pessoas com deficiência nos contextos escolares, que revelam significativas propostas na forma de mudança para uma educação inclusiva. Entretanto, ainda é evidenciado em nossa sociedade, processos de exclusão sobre uma grande parcela da população, que é permeada não apenas por alunos público-alvo da educação especial, mas também por negros, indígenas, mulheres e outros grupos (VINENTE; DUARTE, 2016).

A discussão apresentada, ainda embrionária, buscou retratar a realidade das pessoas com deficiência, por meio da análise das formas de cuidado e educação estabelecidas 
ao longo dos anos, bem como dos desafios encontrados pelos alunos público-alvo da educação especial e profissionais da educação na organização de um sistema educacional equitativo, de qualidade e para todos os alunos.

Nesse contexto, o Brasil, como outros países, têm criado mecanismos para o processo de ensino aprendizagem que valorize as peculiaridades dos alunos e não restrinja a participação efetiva de nenhum sujeito (SOUZA, A. et al., 2012). No entanto, ainda é preciso analisar a efetividade da Lei Brasileira de Inclusão, a disponibilização de recursos e serviços de Tecnologia Assistiva nas escolas, a qualidade e o tipo de serviço do Atendimento Educacional Especializado, a cultura colaborativa nas escolas de ensino regular e, ainda, a participação coletiva das pessoas para a construção de uma sociedade inclusiva.

Reforça-se aqui a preocupação com a formação inicial e continuada dos profissionais docentes para atuação em espaços escolares inclusivos. Nesse sentido, Speroto e Carlesso (2013) já assinalavam em sua produção sobre a lentidão desse contexto, que demanda formação de professores para inclusão de alunos com deficiência na escola regular, a fim de que se considere relevante as necessidades e condições de aprendizado de todos alunos, sejam eles alunos público-alvo da educação especial ou não.

É imprescindível destacar que antes de se fomentar uma formação técnica ou a respeito de práticas pedagógicas inclusivas, é urgente pensar em uma formação que modifique as crenças limitantes a respeito da deficiência e elimine as barreiras atitudinais de todos os profissionais da educação.

Diante disso, entende-se também a necessidade de produções que contemplem essa temática, qual seja, a discussão sobre a importância de propostas tendo-se como referência a educação inclusiva para que se constitua possibilidades para sanar as lacunas deixadas pelo processo de exclusão no cenário escolar.

\section{Referências}

ASSIS, Angelo Adriano Faria de. Inquisição, religiosidade e transformações culturais: a sinagoga das mulheres e a sobrevivência do judaísmo feminino no Brasil colonial Nordeste, séculos XVI-XVII. Revista Brasileira de História, v. 22, n. 43, p. 47-66, 2002.

BRASIL. Lei no 4.024, de 20 de dezembro de 1961. Fixa as Diretrizes e Bases da Educação Nacional (Revogada pela Lei $n^{0}$ 9.394, de 1996, exceto os artigos $6^{\circ}$ a $9^{\circ}$. Estabelece as diretrizes e bases da educação nacional). Brasília, 1961. Disponível em: http://www.planalto.gov.br/ccivil_03/leis/L4024.htm. Acesso em: 05 jun. 2019. 
BRASIL. Decreto $n^{\circ}$ 72.425, de 3 de julho de 1973. Cria o Centro Nacional de Educação Especial (CENESP), e dá outras providências. Brasília: Câmara dos Deputados, 1973. Disponível em: https://www2.camara.leg.br/legin/fed/decret/1970-1979/decreto-72425-3-julho-1973-420888-publicacaooriginal-1-pe.html. Acesso em: 05 jun. 2019.

BRASIL. Portaria Normativa no 13 , de 24 de abril de 2007. Dispõe sobre a criação do "Programa de Implantação de Salas de Recursos Multifuncionais”. Brasília: CNE, 2007. Disponível em: http://portal.mec.gov.br/index. php?option $=$ com_docman\&view $=$ download\&alias $=9935^{-}$ -portaria-13-24-abril-2007\&Itemid=30192. Acesso em: 05 jun. 2019.

BRASIL. Ministério da Educação. Política Nacional de Educação Especial na Perspectiva da Educação Inclusiva. Brasília: Secretaria de Educação Especial, 2008.

BRASIL. Decreto no 6.949, de 25 de agosto de 2009. Promulga a Convenção Internacional sobre os Direitos das Pessoas com Deficiência e seu Protocolo Facultativo, assinados em Nova York, em 30 de março de 2007. Brasília, 2009. Disponível em: https://bit.ly/31UvjUB. Acesso em: o5 jun. 2019.

BRASIL. Lei no 12.796, de 9 de abril de 2013. Altera a Lei no 9.394, de 20 de dezembro de 1996, que estabelece as diretrizes e bases da educação nacional, para dispor sobre a formação dos profissionais da educação e dar outras providências. Brasília, 2013. Disponível em: http://www.planalto.gov.br/ccivil_03/_Ato2011-2014/2013/Lei/L12796. htm. Acesso em: 05 jun. 2019.

BRASIL. Resolução n. 2, de 1 de julho de 2015. Define as Diretrizes Curriculares Nacionais para a formação inicial em nível superior (cursos de licenciatura, cursos de formação pedagógica para graduados e cursos de segunda licenciatura) e para a formação continuada. Brasília: CNE, 2015. Disponível em: http://portal.mec.gov.br/ docman/ agosto-2017-pdf/70431-res-cne-cp-002-03072015-pdf/ file. Acesso em: 17 jun. 2019.

BRASIL. Lei no 13.146, de 6 de julho de 2015. Institui a Lei Brasileira de Inclusão da Pessoa com Deficiência (Estatuto da Pessoa com Deficiência). Brasília, 2015. Disponível em: http://www.planalto.gov.br/ccivil_03/_ato20152018/2015/lei/l13146.htm. Acesso em: o5 jun. 2019.

BORBA, Marcelo Carvalho de; ALMEIDA, Helber Rangel Formiga Leite de; GRACIAS, Telma Aparecida Souza de. 
Pesquisa em ensino e sala de aula: diferentes vozes em uma investigação. 1. ed. Belo Horizonte: Autêntica Editora, 2018.

BUENO, José Geraldo Silveira. Crianças com Necessidades Educativas Especiais, Política Educacional e a Formação de Professores: Generalistas ou Especialistas? Revista Brasileira de Educação Especial, Bauru, v. 5, p. 7-25, 1999.

BUENO, José Geraldo Silveira. Educação especial no Brasil: alguns marcos históricos. In: BUENO, José Geraldo Silveira. Educação especial brasileira: integração/ segregação do aluno diferente. São Paulo: EDUC, 1993. p. 85-99.

CAIADO, Katia Regina Moreno. Aluno com deficiência visual na escola: lembranças e depoimentos. 3. ed. Campinas, SP: Autores Associados, 2014.

COSTA, Vanderlei Balbino da. Inclusão Escolar do Deficiente Visual no Ensino Regular. Jundiaí: Paco Editorial, 2012.

FARIA, Christine Avelar Borges. et al. Atendimento Educacional Especializado: o caso de uma EMEF do Município de Cariacica-ES. Revista Educação Especial, Santa Maria, v. 33, 2020.

FERNANDES, Juliana Medeiros; MASSARO, Munique. Desafios e contradições de professores da Paraíba acerca da inclusão e do atendimento educacional especializado. Olhar de professor, Ponta Grossa, v. 23, p. 1-16, 2020. Disponível em: https://www.revistas2. uepg.br/index. php/olhardeprofessor/article/view/15197. Acesso em: 03 jul. 2020.

FERREIRA, Bárbara Carvalho. et al. Parceria Colaborativa: descrição de uma experiência entre o ensino regular e especial. Revista do Centro de Educação, São Paulo, n. 29, p. 1-7, 2007. Disponível em: https://periodicos.ufsm. br/educacaoespecial/article/view/4137/24 54. Acesso em: 23 jan. 2020.

FILHO, Raimundo Barbosa da Silva; BARBOSA, Elma do Socorro Coutinho. Educação Especial: da prática pedagógica à perspectiva da inclusão. Educação Por Escrito, Porto Alegre, v. 6, n. 2, p. 353-368, 2015.

KRANZ, Claúdia Rosana. O desenho universal pedagógico na educação matemática inclusiva. São Paulo: Editora Livraria da Física, 2015. 
MANTOAN, Maria Teresa Eglér. Inclusão escolar: o que é? por quê? como fazer?. São Paulo: Moderna, 2003.

MATOS; Selma Norberto; MENDES, Enicéia Gonçalves. Demandas decorrentes da inclusão escolar. Revista Educação Especial, Santa Maria, v. 27, n. 48, p. 27-40, 2014. Disponível: https://periodicos.ufsm.br/educacaoespecial/ article/view/ 8796/pdf. Acesso em: 23 jan. 2020.

MENDES, Enicéia Gonçalves. Breve histórico da educação especial no Brasil. Revista Educación y Pedagogía, Medellín, v. 22, n. 57, 2010.

MENDES, Enicéia Gonçalves; VILARONGA, Carla Ariela Rios; ZERBATO, Ana Paula. Ensino colaborativo como apoio à inclusão escolar: unindo esforços entre educação comum e especial. São Carlos: UFSCar, 2014.

MENDES, Enicéia Gonçalves; MALHEIRO, Cícera Aparecida Lima. Salas de recursos multifuncionais: é possível um serviço "tamanho único" de atendimento educacional especializado? In: MIRANDA; Theresinha Guimarães; GALVÃO FILHO; Teófilo Alves (org.). O professor e a educação inclusiva: formação, práticas e lugares. 1. ed. Salvador: EDUFBA, 2012. p. 343-351.

MIRANDA, Arlete Aparecida Bertoldo. Educação especial no Brasil: desenvolvimento histórico. Cadernos de História da Educação, Uberlândia, v. 7, 2008.

ONU. Resolução 2.542 de 1975. Declaração dos Direitos das Pessoas Deficientes. Resolução aprovada pela Assembleia Geral da Organização das Nações Unidas, 1975. Disponível em: http://portal.mec.gov.br/seesp/arquivos/ pdf/dec_def.pdf. Acesso em: 05 jun. 2019.

ROCHA, Mayra Rodrigues; LIMA, Maria Carmem Bezerra. Formação de professores para escolas inclusivas: o lugar da inclusão no currículo dos cursos de formação de professores da UESPI. In: EVÊNCIO, Kátia Maria de Moura (org.). Educação inclusiva: diversos olhares entre teorias e práticas. 1. ed. Curitiba: Appris, 2018. p. 53-81.

SANTOS, Vivian; TORRES, Josiane Pereira; MENDES, Enicéia Gonçalves. Análise da produção científica brasileira sobre o Atendimento Educacional especializado. Revista Educação, Batatais, v. 6, n. 3, p. 11-24, 2016.

SANTOS, Edimar Adalberto dos; MOURA, Kátia Maria de. A relação professor e aluno e sua influência no processo de inclusão escolar. In: EVÊNCIO, Kátia Maria de Moura (org.). Educação inclusiva: diversos olhares entre teorias e práticas. 1. ed. Curitiba: Appris, 2018. p. 25-51. 
SANTOS, Júlio Maia Ferreira dos. Dimensões e diálogos de exclusão: Um caminho para inclusão. In: SANTOS, Mônica Pereira dos Santos; PAULINO, Marcos Moreira (org.). Inclusão em educação: culturas, políticas e práticas. São Paulo: Cortez, 2006. p. 17-29.

SERRA, Dayse Carla Genero. Inclusão e Ambiente Escolar. In: SANTOS, Mônica Pereira dos Santos; PAULINO, Marcos Moreira (org.). Inclusão em educação: culturas, políticas e práticas. São Paulo: Cortez, 2006. p. 31-44.

SILVA, Kátia Regina Xavier da. Expressão da criatividade na prática pedagógica e a luta pela inclusão em Educação: tecendo relações. In: SANTOS, Mônica Pereira dos Santos; PAULINO, Marcos Moreira (org.). Inclusão em educação: culturas, políticas e práticas. São Paulo: Cortez, 2006. p. $45-57$.

SOUZA, Ana Claudia de. et al. A inclusão escolar no município de Paranaíba (MS): reflexões sobre a atuação profissional do monitor de alunos com deficiência. Revista Pedagógica, Chapecó, ano 16, v. 02, n. 29, p. 635-664, 2012.

SOUZA, Rita de Cácia Santos. Educação especial em Sergipe do século XIX ao início do século XX: cuidar e educar para civilizar. 2009. 196 f. Tese (Doutorado em Educação) - Faculdade de Educação, Universidade Federal da Bahia, Salvador, 2009.

SPEROTO, Juciele Luisa Michalak; CARLESSO, Dariane. Inclusão na educação infantil: a experiência de uma criança com Síndrome de Down. Revista Pedagógica, Chapecó, ano 17, v. 1, n. 30, p. 667-698, 2013.

UNESCO. Declaração Mundial sobre Educação para Todos: satisfação das necessidades básicas de aprendizagem. Jomtien, 1990.

UNESCO. Declaração de Salamanca: sobre princípios, políticas e práticas na área das necessidades educativas especiais. Salamanca: UNESCO, 1994. Disponível em: http://portal.mec.gov.br/seesp/arquivos/pdf/salamanca. pdf. Acesso em: 05 jun. 2019.

VIEIRA, Alexandro Braga; RAMOS, Ines de Oliveira; SIMÕES, Renata Duarte. Narrativas de professores e pedagogos sobre a deficiência: implicações no acesso ao currículo escolar. Revista Educação Especial, Santa Maria, v. 32, 2019.

VINENTE, Samuel; DUARTE, Márcia. Universalização do atendimento escolar aos estudantes público-alvo da Edu- 
cação Especial: notas sobre os planos nacionais de educação (2001 e 2014). Revista Pedagógica, Chapecó, n. 38, v. 18, p. 184-207, 2016.

WALBER, Vera Beatris; SILVA, Rosane Neves da. As práticas de cuidado e a questão da deficiência: integração ou inclusão? Estudos de Psicologia, Campinas, v. 26, n. 1, p. 29-37, 2006.

Enviado em: 17-07-2020 Aceito em:26-08-2020

Publicado em: 30-10-2020 